\title{
Control of Upstream Austenite Grain Coarsening during the Thin-Slab Cast Direct-Rolling (TSCDR) Process
}

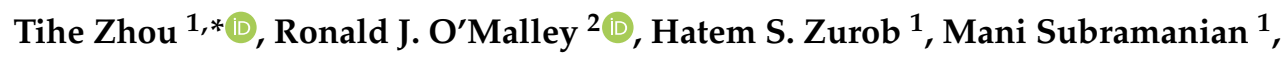 \\ Sang-Hyun $\mathrm{Cho}^{3}$ and Peng Zhang ${ }^{3}$ \\ 1 Department of Materials Science and Engineering, McMaster University, 1280 Main Street West, Hamilton, \\ ON L8S 4L7, Canada; zurobh@mcmaster.ca (H.S.Z.); subraman@mcmaster.ca (M.S.) \\ 2 Department of Materials Science and Engineering, Missouri University of Science \& Technology, \\ 1400 N. Bishop Ave., Rolla, MO 65409-0330, USA; omalleyr@mst.edu \\ 3 Algoma Inc. 105 West Street, Sault Ste. Marie, ON P6A 7B4, Canada; Sang-Hyun.Cho@algoma.com (S.-H.C.); \\ peng.zhang@algoma.com (P.Z.) \\ * Correspondence: tom.zhou@stelco.com; Tel.: +1-519-587-4541 (ext. 5398)
}

Received: 27 December 2018; Accepted: 29 January 2019; Published: 1 February 2019

\begin{abstract}
Thin-slab cast direct-rolling (TSCDR) has become a major process for flat-rolled production. However, the elimination of slab reheating and limited number of thermomechanical deformation passes leave fewer opportunities for austenite grain refinement, resulting in some large grains persisting in the final microstructure. In order to achieve excellent ductile to brittle transition temperature (DBTT) and drop weight tear test (DWTT) properties in thicker gauge high-strength low-alloy products, it is necessary to control austenite grain coarsening prior to the onset of thermomechanical processing. This contribution proposes a suite of methods to refine the austenite grain from both theoretical and practical perspectives, including: increasing cooling rate during casting, liquid core reduction, increasing austenite nucleation sites during the delta-ferrite to austenite phase transformation, controlling holding furnace temperature and time to avoid austenite coarsening, and producing a new alloy with two-phase pinning to arrest grain coarsening. These methodologies can not only refine austenite grain size in the slab center, but also improve the slab homogeneity.
\end{abstract}

Keywords: thin-slab cast direct-rolling; austenite grain coarsening; grain growth control; liquid core reduction; secondary cooling; two-phase pinning

\section{Introduction}

Owing to low capital and operating cost, thin-slab cast direct-rolling (TSCDR) has become a major process for hot flat-rolled production since Nucor started the first thin slab caster, directly linked to a hot rolling mill, back in 1989. This process is based on a novel funnel mold caster, which can produce a thin slab of thickness from 50 to $90 \mathrm{~mm}$, instead of the conventional continuous casting slab thicknesses of 200 to $250 \mathrm{~mm}$ [1,2]. Figure 1 is an example of the TSCDR process at Algoma Inc. The liquid steel is fed via the ladle and tundish into a funnel-shaped copper mold with primary cooling control. Solidification initiates on the mold wall and the external solidified shell increases in thickness as the steel strand passes through the mold. Based on the steel grades and slab thickness, the casting speed can be from 2.5 to $6.5 \mathrm{~m} / \mathrm{min}$. Once leaving the mold, the thin slab passes through the secondary-cooling zone and solidification continues. The secondary-cooling zone has eight segments with multi-point bending and unbending, with $12.7-\mathrm{m}$ containment length, by using air mist cooling. The liquid core reduction system can refine the as-cast microstructure and reduce the centerline segregation and solidification-related defects. The continuous slab is cut to length and then sent to 
the roller hearth soaking furnace. To maximize the use of the rolling capacity, the thin slab caster has two strands along with two shuttle furnaces, which can transfer the slab sideways to allow the two strands to feed a single rolling mill. The slab is rolled in a single pass roughing mill after descaling, then goes through the heated transfer table and is rolled in the six-stand finishing mill; the resulting hot strip then passes through the run-out table with a laminar cooling system and is coiled at the down coiler [3].

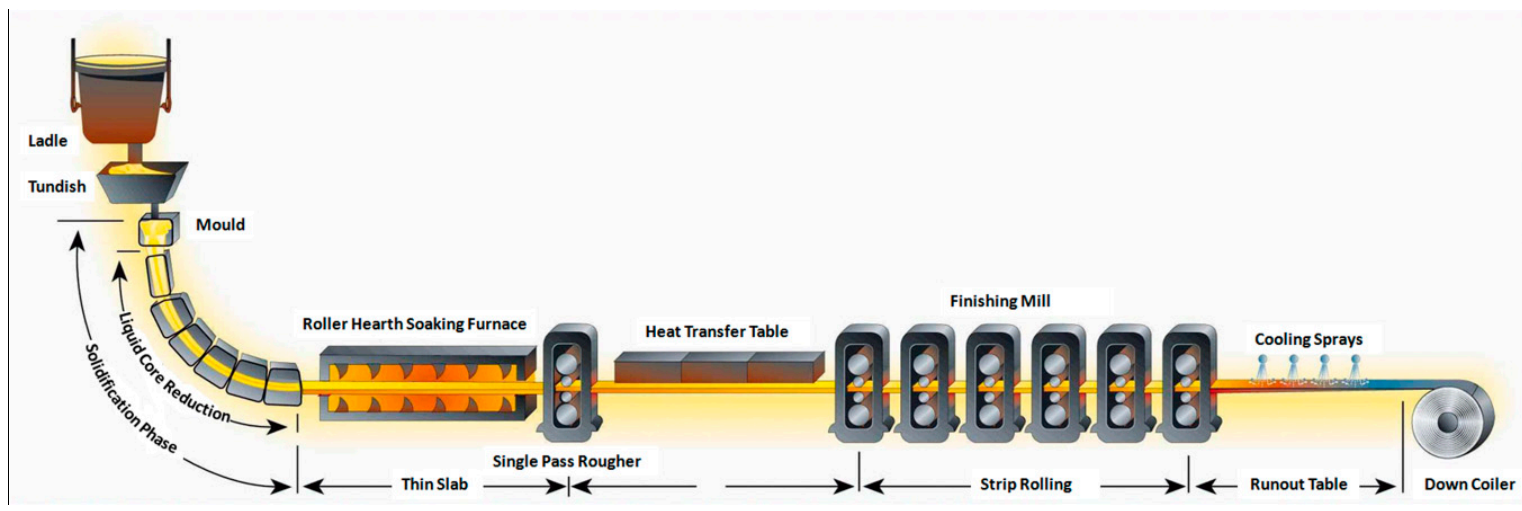

Figure 1. Thin slab casting direct strip production complex at Algoma Inc. [3].

TSCDR mills currently produce a variety of steel grades, including interstitial free steel, low carbon to medium carbon steel, high-strength low-alloy, and advanced high strength multiphase steel grades [1]. Recently, great effort has been placed on using this process to produce high grade micro alloyed steels that can be utilized in bridge guard rails, wind turbine towers, rail cars, and oil and gas pipelines, with stringent low-temperature ductile to brittle transition (DBTT) and drop weight tear test (DWTT) requirements to maintain structural integrity and safety over several decades of service [4,5]. It well established that refining austenite grain size before pancaking can improve DBTT and DWTT properties [6]. In most cases, these applications require a hot band thickness of $10 \mathrm{~mm}$ or more. This requirement challenges the TSCDR process, because the ratio of the thickness of the initial as-cast slab to that of the final product is only of the order of 5-7 to 1 . It has been proven that production of higher high strength low alloyed (HSLA) grades is very difficult, owing to the presence of extremely large austenite grains in the center of the slab prior to thermomechanical processing [7]. The limited number of thermomechanical deformation passes available in the TSCDR process cannot refine these larger grains $[8,9]$. In order to achieve uniform and finer microstructure, it is very important to control the upstream austenite grain coarsening before the slab enters the roughing mill. This contribution will focus on refining austenite grain by increasing the cooling rate during solidification, increasing nucleation sites for delta-ferrite by liquid core reduction, and increasing austenite nucleation sites during the delta-ferrite to austenite phase transformation, as well as controlling austenite coarsening inside the holding furnace. In addition, the possibility of rolling new alloy with two-phase pinning is also discussed.

\section{Materials, Experimental Procedure, and Model Setup}

The experimental materials in this study consisted of an HSLA based American Petroleum Institute (API) X70 cast slab sample from industry, as well as an Fe-Al model alloy with $1.5 \% \mathrm{Al}$ addition to generate delta/austenite two-phase microstructure at different temperatures. The two chemistries are compared in Table 1 . The addition of Al in the Fe-Al model alloy can stabilize delta-ferrite down to room temperature. A two-phase mixture of delta-ferrite and austenite will exist at temperatures between $1310{ }^{\circ} \mathrm{C}$ and the eutectoid temperature. The Fe-Al model alloy was prepared by induction melting at CANMET Materials Technology Lab (Hamilton, ON, Canada); the as-received microstructure was delta-ferrite with grain size of approximately $85 \mu \mathrm{m}$, after pilot mill hot rolling to the thickness of $10 \mathrm{~mm}$. 
Table 1. Chemical composition of the new alloy used in this investigation (wt \%).

\begin{tabular}{cccccccc}
\hline wt $\%$ & $\mathbf{C}$ & $\mathbf{M n}$ & $\mathbf{S i}$ & $\mathbf{A l}$ & $\mathbf{T i}$ & $\mathbf{N b}$ & $\mathbf{N}$ \\
\hline API X70 & 0.05 & 1.60 & 0.30 & 0.0037 & 0.0012 & 0.07 & 0.0060 \\
Fe-Al model alloy & 0.051 & 1.00 & 0.36 & 1.5 & 0 & 0 & 0 \\
\hline
\end{tabular}

In order to quantify the grain coarsening at high temperature, a simple non-isothermal grain growth model [9] was utilized to capture the evolution of grain growth at different stages of the TSCDR process. Starting with the simple equation:

$$
\frac{\mathrm{d} \bar{R}}{\mathrm{~d} t}=\alpha M(t) \frac{2 \gamma_{\mathrm{gb}}}{\bar{R}}
$$

then integrating with respect to time, which led to:

$$
\bar{R}^{2}=\bar{R}_{0}^{2}+4 \gamma_{\mathrm{gb}} \int_{0}^{t} \alpha M(t) \mathrm{d} t
$$

where $\bar{R}$ is the mean radius of an individual grain, $\bar{R}_{0}$ is the initial grain radius, and $\gamma_{\mathrm{gb}}$ denotes the grain boundary energy per unit of area. A reasonable value of $0.8 \mathrm{~J} \cdot \mathrm{m}^{-2}$ [10] was used for the calculation. $\alpha$ is a shape factor with value of $\sim 1.5$ [11], and $M(t)$ is the mobility of the grain boundaries [9,12]. Delta-ferrite grain boundary mobility is shown as [9]:

$$
M_{\delta}(t)=\frac{0.7075}{T(t)} \times \exp \left(\frac{-20,995.43}{T(t)}\right)
$$

While austenite grain boundary mobility is listed as [9]:

$$
M_{\gamma}(t)=\frac{0.3072}{T(t)} \times \exp \left(\frac{-20,837.14}{T(t)}\right)
$$

In this equation, $T(t)$ is an expression for the temperature as a function of time, which was obtained either experimentally from the data recorded, using a thermocouple, or the temperature profiles during the TSCDR process predicted by the heat transfer model. The details are in the Appendix A.

During a typical TSCDR practice, for instance, Table 1 chemistry, Ti concentration is very low and large TiN particles are formed in the liquid during the late stages of solidification. These particles coarsen during the subsequent solid-state process at high temperature $[13,14]$. These large TiN particles exert a very small particle pinning effect [15]. Strong particle pinning conditions are not encountered until fine $\mathrm{Nb}(\mathrm{C}, \mathrm{N})$ precipitates are formed during thermomechanical processing [16-18]. In addition, according to Zurob et al [19], the solute-drag effect of all alloying elements was shown to be negligible at temperatures above $1200{ }^{\circ} \mathrm{C}$. Therefore, Equation (2) can be used to model the grain-size evolution during the TSCDR process up to the point where the slabs exit the homogenization furnace prior to thermomechanical processing at the roughing mill.

To validate the grain growth model, a $70 \mathrm{~mm}$ and an $85 \mathrm{~mm}$ thickness slab of API X70 were sampled after solidification prior to entering the twin roller hearth tunnel furnaces. The slab crops were sectioned to measure the austenite grain size at various distances from the slab surface. All the samples were prepared using standard metallographic techniques. The prior austenite grain boundaries were revealed using an aqueous solution of picric acid with sodium dodecylbenzene sulfonate, with additions of hydrochloric acid for the different chemistry. Microstructure was investigated using optical and scanning electron microscopy. The image analysis was performed using Clemex PE5.0 software (Clemex Technologies Inc., Longueuil, QC, Canada). The grain size was measured using the area intercept method and the true three-dimensional grain diameter was calculated as 1.382 times the linear intercept diameter [20]. 


\section{Results and Discussions}

\subsection{Microstructure and Model Validation}

The microstructure of the industrially-supplied TSCDR 85- and 70-mm thick slabs of API X70 steel are shown in Figures 2 and 3, respectively. At the surface of the $85 \mathrm{~mm}$ API X70 slab, the prior austenite grain size was about $50 \mu \mathrm{m}$. At the center of the slab, the prior austenite grain size was as large as $1151 \mu \mathrm{m}$. While, the prior austenite grain size at the surface of the $70 \mathrm{~mm}$ API X70 slab was about $14 \mu \mathrm{m}$, and at the center of the slab was about $858 \mu \mathrm{m}$.

Figures 2 and 3 indicated that the industrial TSCDR as-cast microstructure was non-uniform with extremely large grains at the slab center, and that the $70 \mathrm{~mm}$ thick slab had a finer austenite grain size compared to the $80 \mathrm{~mm}$ slab.

The grain growth model Equation (2) can be used to calculate the delta-ferrite and austenite grain size evolution at different positions in the slab. The important points that are required to be considered is that of the initial grain size $\bar{R}_{0}$ and the cooling path $(T(t)$, in Equations (3) and (4)), which varies from the surface to the center of the slab, leading to grain-size variations. To understand the HSLA microstructure evolution during the TSCDR process, THERMO-CALC (Thermo-Calc Software AB, Solna, Sweden) was used to predict the relevant transformation temperatures for API X70 and the Fe-Al model alloy using the TCFE6 database [21]. The results are given in Table 2.

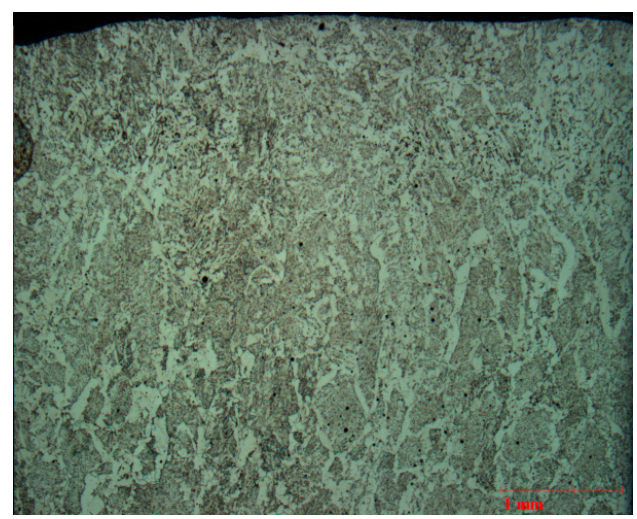

(a)

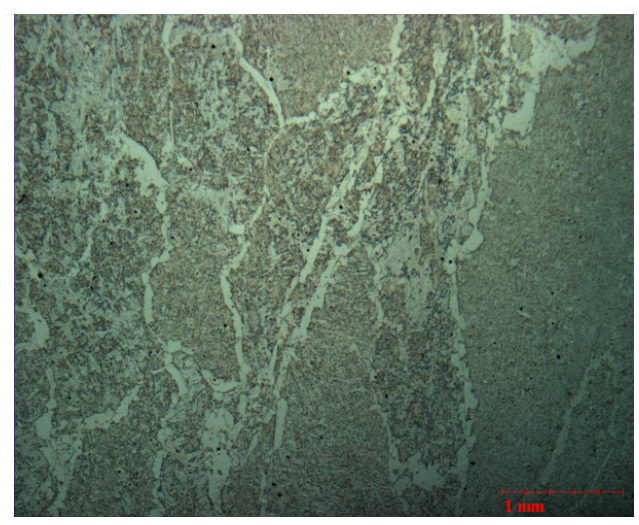

(c)

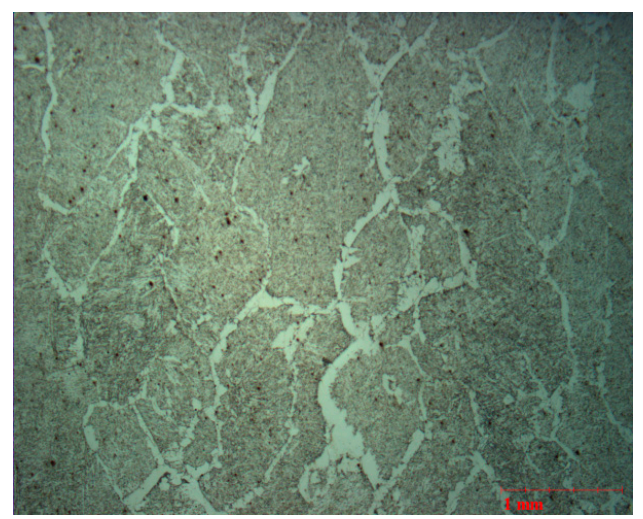

(b)

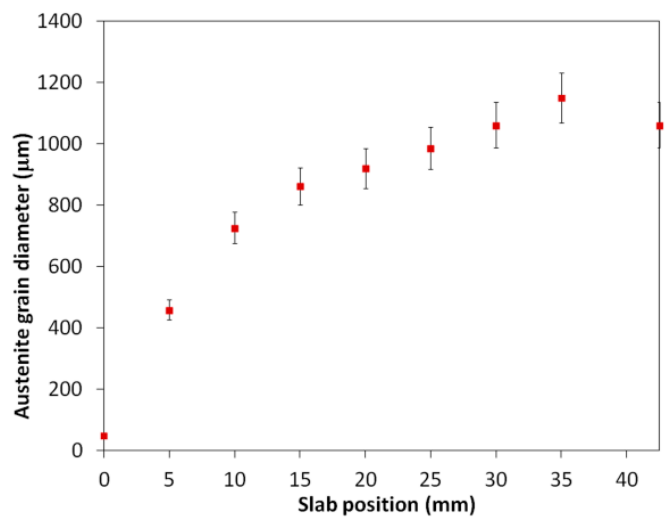

(d)

Figure 2. 85-mm slab austenite grain size evolution of American Petroleum Institute (API) X70 from the industrial thin slab casting process: (a) close to slab surface; (b) $20 \mathrm{~mm}$ from the slab surface; (c) close to the slab center; and (d) summary of the measured austenite grain size with distance from slab surface to center. 


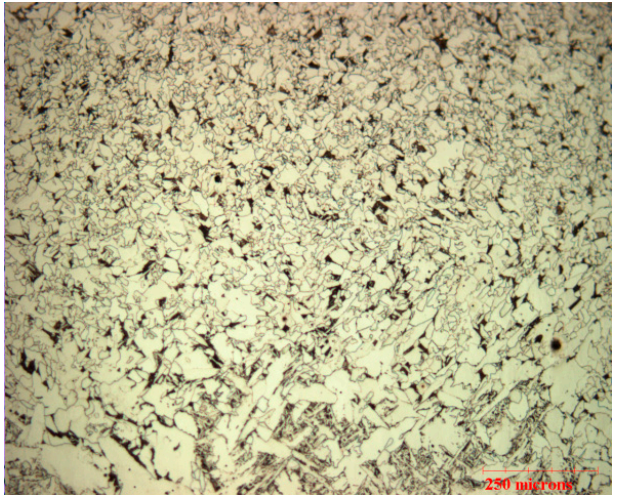

(a)

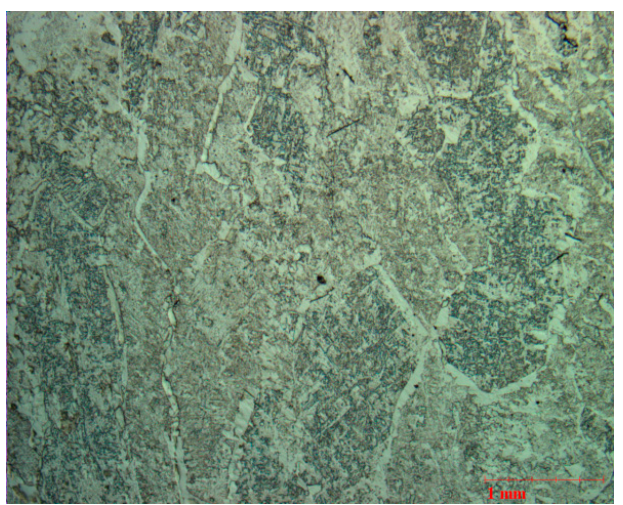

(c)

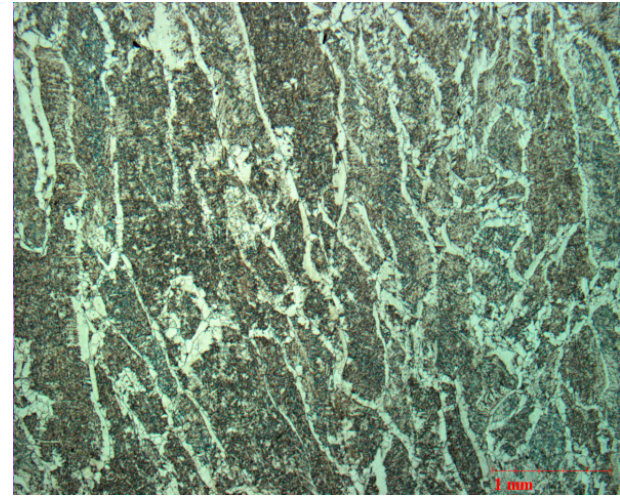

(b)

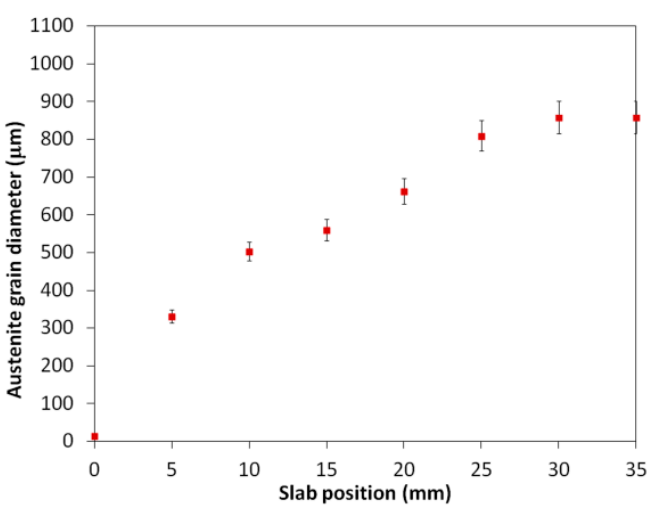

(d)

Figure 3. 70-mm slab austenite grain size evolution of API X70 from the industrial thin slab casting process: (a) close to slab surface; (b) $20 \mathrm{~mm}$ from the slab surface; (c) close to the slab center; and (d) summary of the measured austenite grain size with distance from slab surface to center.

Table 2. Phase transformation temperature of API X 70.

\begin{tabular}{cccccc}
\hline Phase & Liquid & Liquid + Delta & Delta & Delta + Austenite & Austenite \\
\hline API X 70 $\left({ }^{\circ} \mathrm{C}\right)$ & $>1524$ & $1524-1496$ & $1496-1477$ & $1477-1448$ & $1448-852$ \\
Fe-Al alloy $\left({ }^{\circ} \mathrm{C}\right)$ & $>1530$ & $1530-1500$ & $1500-1412$ & $1412-734$ & - \\
\hline
\end{tabular}

In this study, we have not attempted to model the delta-ferrite to austenite transformation. Instead we simply assumed that the delta grain growth occurred down to $1477^{\circ} \mathrm{C}$ and austenite grain growth occurred after the delta-ferrite to austenite phase transformation. The secondary dendrite arm spacing (SDAS) was used as the initial delta-ferrite grain size, $\bar{R}_{0}$, which was calculated using the CON1D V7.0 slab casting heat transfer model, assuming the casting speed of $3.4 \mathrm{~m} / \mathrm{min}$ [22], as shown in Figure 4 a. The initial austenite grain size was presumed to be smaller than the final delta grain size, and was divided by a factor of $3[23,24]$ to account for the effect of grain refinement due to the delta-ferrite to austenite transformation in the grain size calculation. Finally, the cooling path $T(t)$ at each point of the slab was also estimated by the CON1D V7.0 model [22]. For example, Figure $4 \mathrm{~b}$ shows the temperature paths at the surface, 5, 10, and $20 \mathrm{~mm}$ below the surface, and the center of the API X70 $85 \mathrm{~mm}$ slab that was cast with $3.4 \mathrm{~m} / \mathrm{min}$ casting speed. Due to the spray jet cooling and the high local heat extraction, when the segment rolls directly contacted the slab, the temperature curve on the slab surface showed an irregular trend. Nonetheless, this irregular trend should not interfere with the interpretation of the grain growth with the slab position during the TSCDR process. 


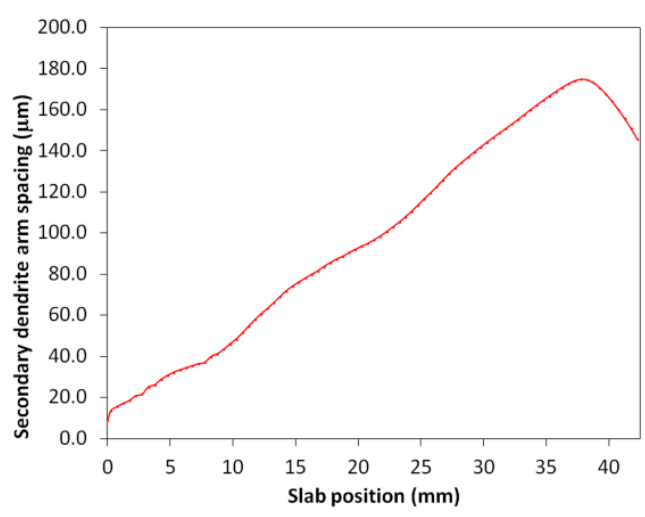

(a)

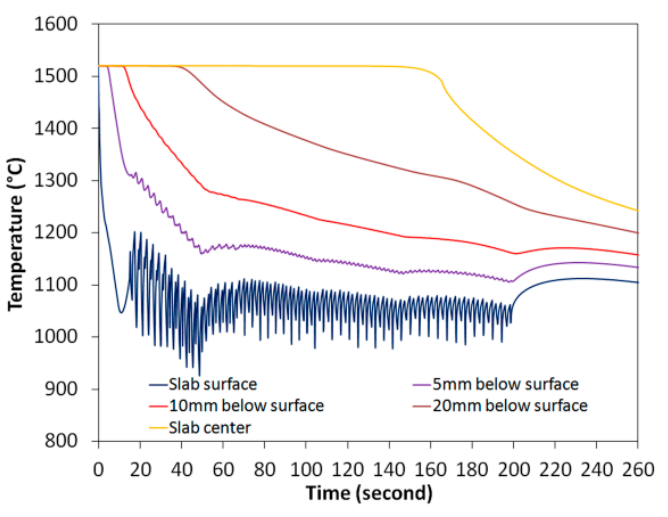

(b)

Figure 4. CON1D V7.0 slab casting heat transfer model predicted: (a) secondary dendrite arm spacing as a function of position within the API X70 slab; and (b) temperature paths at the surface, 5, 10, and 20 $\mathrm{mm}$ below the surface, and the center of the slab.

Using Equations (2) and (3), an example of delta grain size evolution with time at $5 \mathrm{~mm}$ below the slab surface is shown in Figure 5a. The austenite grain size evolution at the same position ( $5 \mathrm{~mm}$ below the surface) with time just before leaving the holding furnace, by using Equations (2) and (4), is shown in Figure $5 b$. The solid line represents the model predicted austenite grain diameter and the dashed line represents the temperature profile in the TSCDR process at the corresponding slab position.

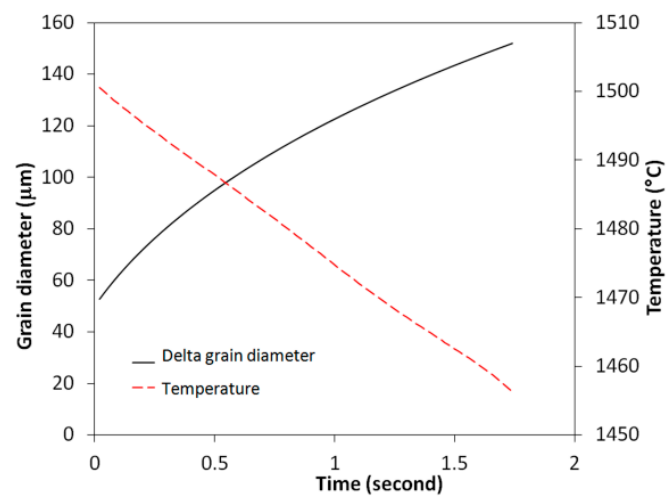

(a)

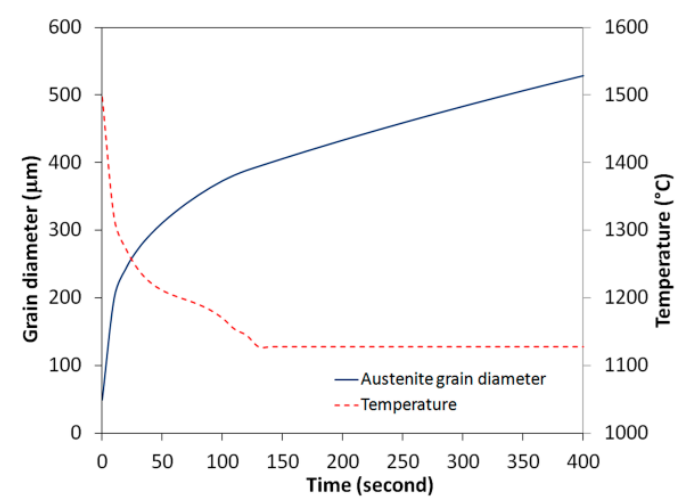

(b)

Figure 5. (a) The predicted delta grain size evolution with time $5 \mathrm{~mm}$ below the slab surface; and (b) the predicted austenite grain size evolution at the same position before entering the roller hearth holding furnace.

Similar calculations were conducted as a function of the slab thickness. Figure 6a shows the predicted delta grain size as a function of slab position, just before the onset of the delta-ferrite to austenite transformation. The solid diamonds are the calculated delta grain sizes; the solid line is used to highlight the trends of grain size change with distance from the surface to center of the slab. In addition, the austenite grain size could be calculated when the slab was about to enter the holding furnace, and upon leaving the holding furnace prior to entering the roughing mill.

Figure $6 \mathrm{~b}$ shows the calculated austenite grain size with slab thickness when the slab is about to enter the holding furnace. The solid diamonds and solid lines follow the same notation for delta grains as noted previously. The experimentally measured austenite grain size from the $85 \mathrm{~mm}$ slab from Figure $2 \mathrm{~d}$ (solid squares) is superimposed for comparison. It indicates that very good agreement was obtained between the model prediction and the measured austenite grain size as a function of the slab position. This provides strong support that the normal grain growth model developed here can be used 
to predict austenite grain growth at high temperatures prior to the thermomechanical processing. The calculated austenite grain size for the $70 \mathrm{~mm}$ slab and the corresponding experimental measurements (Figure 3d) with slab position is shown in Figure 6c. Once again, the predicted austenite grain size was in good agreement with the experimental data as a function of slab position. This agreement further validates the grain growth treatment employed here and supports the applications of the model in the following sections.

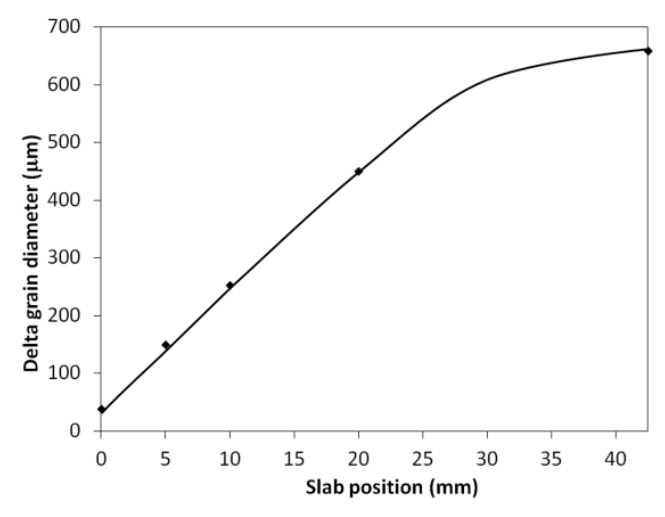

(a)

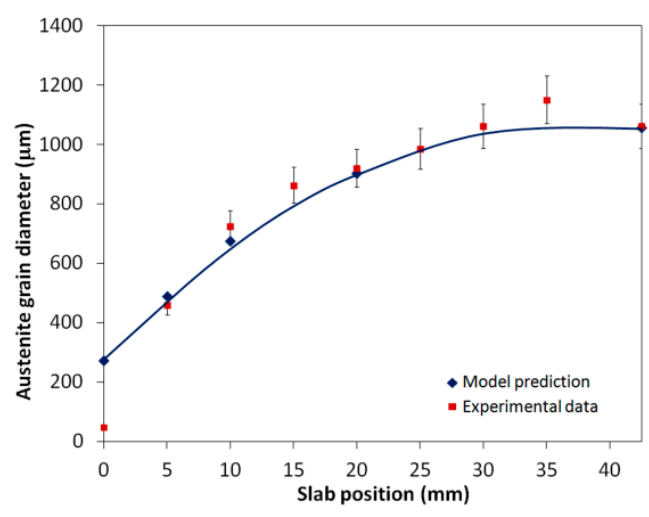

(b)

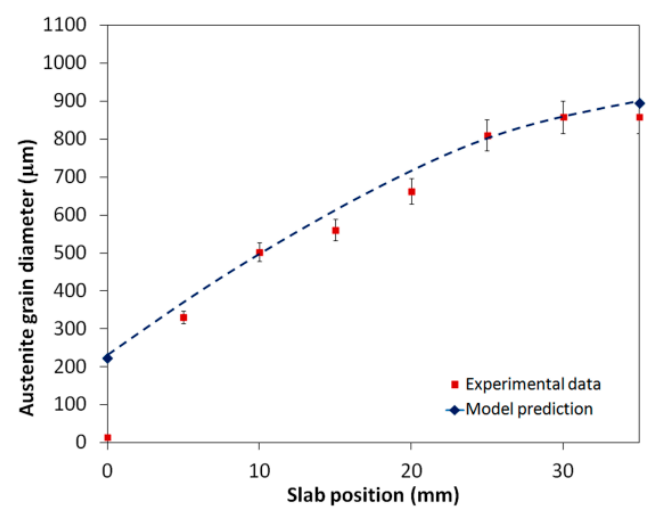

(c)

Figure 6. (a) The predicted delta grain size as a function of slab position; (b) comparison of model prediction and experimental measurement of austenite grain size with slab position before the $85 \mathrm{~mm}$ slab enters the holding furnace; and (c) comparison of model prediction and experimental measurement of austenite grain size with slab position before the $70 \mathrm{~mm}$ slab entering the holding furnace.

\subsection{Increasing Cooling Rate to Refine As-Cast Microstructure}

Reducing the slab thickness can increase the cooling rate at the slab center, which can refine the austenite grain at the slab center and reduce the non-uniformity of the as-cast microstructure. In what follows, the consequences of reducing the slab thickness from $85 \mathrm{~mm}$ to 50 and $30 \mathrm{~mm}$ are examined assuming that the only change is the enhanced cooling rate of the slab [25-27]. In order to determine the cooling rate and the initial secondary dendrite arm spacing, the CON1D V7.0 slab casting heat transfer model [22] was used for slabs of 85, 50, and $30 \mathrm{~mm}$ slab thicknesses, as shown in Figure 7.

The initial delta-ferrite grain size was, once again, taken to be SDAS; therefore, the model prediction of delta grain size as a function of position for the 30 and $50 \mathrm{~mm}$ thin slabs just before the onset of the delta to gamma transformation are shown in Figure 8a, which also includes, for comparison, the results shown earlier for the 70 and $85 \mathrm{~mm}$ slabs. The calculated austenite grain size before entering the homogenization furnace is shown in Figure $8 \mathrm{~b}$. The symbols in these Figures have the same meaning as discussed previously. 


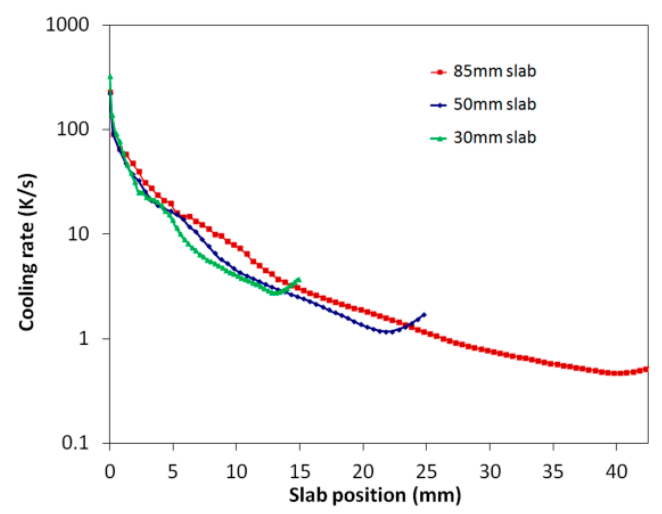

(a)

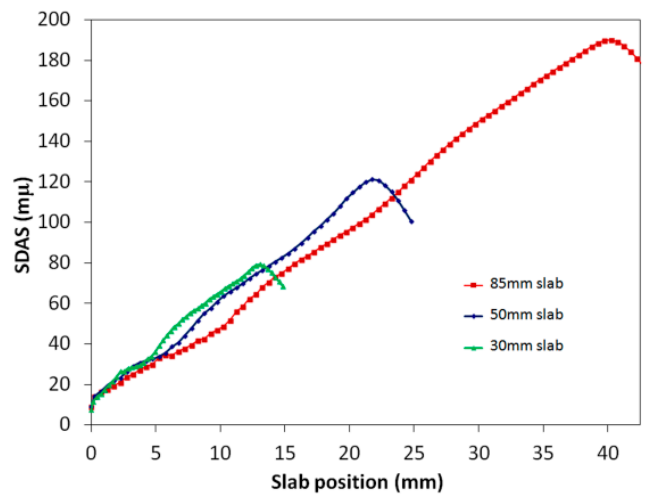

(b)

Figure 7. CON1D V7.0 slab casting heat transfer model predicted: (a) cooling curves; and (b) secondary dendrite arm spacing (SDAS) at different positions of 30, 50, and $85 \mathrm{~mm}$ slabs.

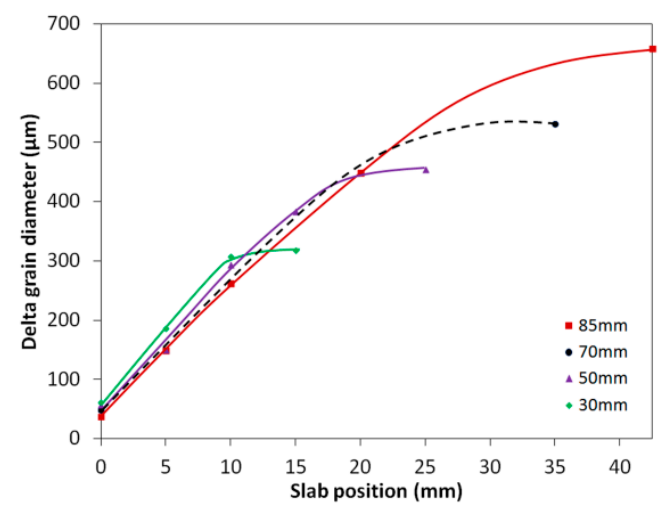

(a)

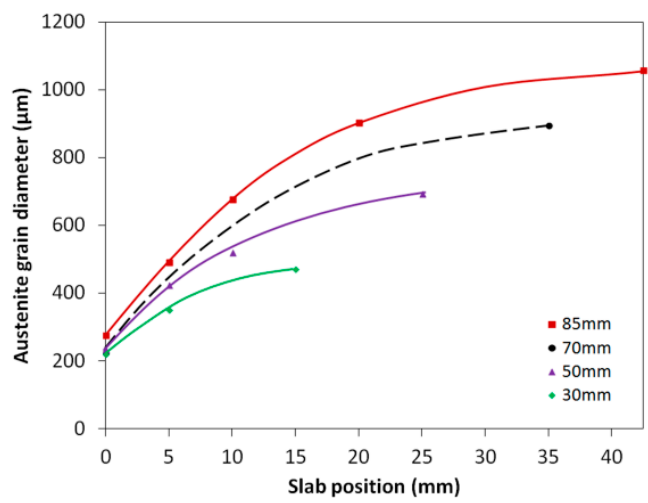

(b)

Figure 8. (a) The predicted delta grain size of $30,50,70$, and $85 \mathrm{~mm}$ slabs as a function of slab position just before the onset of the delta to gamma transformation; (b) the predicted austenite grain size of $85,70,50$, and $30 \mathrm{~mm}$ slabs as a function of slab position when the slab is about to enter the homogenization furnace.

It is clear from these calculations that, due to the enhanced cooling rate, austenite grains at the center of the thinner slabs had greatly reduced in size. When the slabs were about to enter the homogenization furnace, the austenite grain size at the center of the $85 \mathrm{~mm}$ thick slab was about $1058 \mu \mathrm{m}$. However, the grain size was $896 \mu \mathrm{m}$ at the center of the $70 \mathrm{~mm}$ thick slab, $693 \mu \mathrm{m}$ at the center of the $50 \mathrm{~mm}$ thick slab, and $470 \mu \mathrm{m}$ at the center of the $30 \mathrm{~mm}$ slab. In addition, the homogeneity of the microstructure had improved by increasing the cooling rate; the ratio of largest grain size to smallest grain size was 3.8 to 1 for the $85 \mathrm{~mm}$ thick slab, 2.8 to 1 for the $50 \mathrm{~mm}$ thick slab, and 2.1 to 1 for the $30 \mathrm{~mm}$ slab. Therefore, one can conclude that reducing the slab thickness can refine and homogenize the as-cast microstructure due to the enhanced cooling rate at the center of the slab. Experimental measurements of $85 \mathrm{~mm}$ (Figure 2) and $70 \mathrm{~mm}$ (Figure 3) industrial slab austenite grain sizes, using the distance from the slab surface to center, demonstrated the validity and technological merit of the increased cooling on reducing austenite grains at the center of the slab. The austenite grain size could be reduced from 1151 to $858 \mu \mathrm{m}$ if the casting slab thickness was reduced from 85 to $70 \mathrm{~mm}$. The main difficulty in applying this method is that it requires changing the layout of the TSCDR process for casting thinner slabs, such as 50 and $30 \mathrm{~mm}$ thick slabs. In addition, the smaller slab thickness will further reduce the amount of thermomechanical processing that can be performed downstream, resulting in a larger average grain size, and possibly more grain size non-uniformity despite the improved initial microstructure. Thus, an optimum thickness could be determined by 
considering both the solidification and grain growth (as described above) as well as the subsequent thermomechanical processing.

It is well established that as-cast microstructure is a function of the solidification rate $(V)$ and temperature gradient $(G)$ ahead of the solid-liquid front. The effect of the temperature gradient and velocity on the primary dendrite arm spacing can be summarized in the following equation [28,29]:

$$
\lambda_{1}=A_{1} G^{-m} V^{-n}
$$

where $\lambda_{1}$ is the primary arm spacing, $G$ is the average temperature gradient in front of tip of dendrite in the liquid side, and $V$ is average solidification velocity. $A_{1}, m$, and $n$ are constants. For the secondary dendrite arm spacing $\lambda_{2}$, the most widely accepted expression for the relationship between $\lambda_{2}$ and cooling rate $(G V)[30,31]$ is:

$$
\lambda_{2}=B_{1}(G V)^{-n}
$$

where $B_{1}$ and $n$ are constants. Increasing secondary cooling with restricted casting speed will increase the cooling rate $(G V)$. As a result, the primary and secondary dendrite arm spacing will decrease based on Equations (5) and (6). Figure 9a shows the Algoma DSPC model-predicted slab surface temperatures using different secondary cooling set-ups (the water loops configuration of DSPC is illustrated in Figure 9b). The solid diamonds are the slab surface temperatures for the standard spray cooling set-up used for low carbon steels, $0.6 \mathrm{~L} / \mathrm{kg}$ of hot steel, and the increased secondary cooling, $1.4 \mathrm{~L} / \mathrm{kg}$ of hot steel, is used for HSLA steels (solid squares in Figure 9a). When the liquid superheat was above $15^{\circ} \mathrm{C}$, the casting speed was restricted to $3.0 \mathrm{~m} / \mathrm{min}$; once the liquid superheat was below $10{ }^{\circ} \mathrm{C}$, the casting speed could be increased to $3.4 \mathrm{~m} / \mathrm{min}$. Based on the above setup, the predicted $85-\mathrm{mm}$ slab surface and center temperature profiles using increased secondary cooling, with a casting speed of $3.0 \mathrm{~m} / \mathrm{min}$, using the CON1D V7.0 model are shown in Figure 9c. Figure 9d shows austenite grain size with slab position using standard cooling and increased secondary cooling. The solid line highlights the trends of grain refinement with distance from the slab surface to the center. The increased secondary cooling practice was predicted to have a much finer austenite grain size than the standard spray practice at both the surface and center of the slab; austenite grain size was reduced from 276 to $253 \mu \mathrm{m}$ at the surface and from 1058 to $808 \mu \mathrm{m}$ at the slab center.

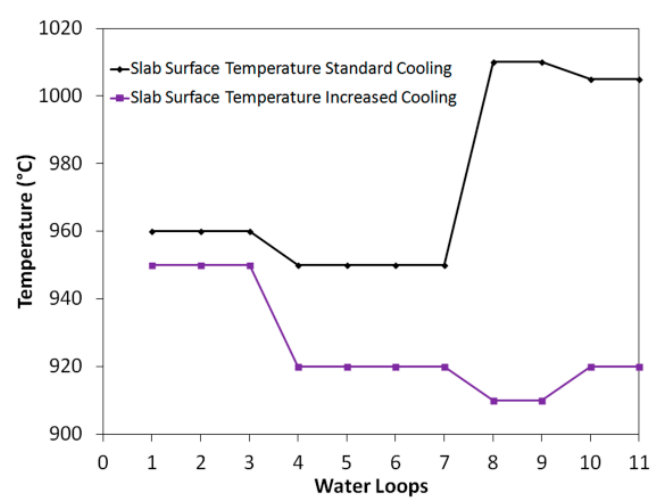

(a)

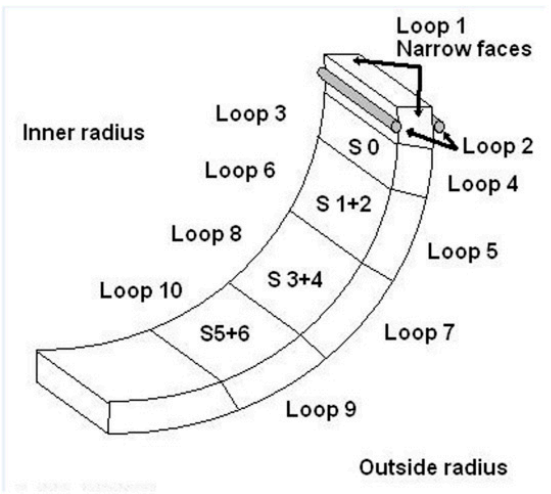

(b)

Figure 9. Cont. 


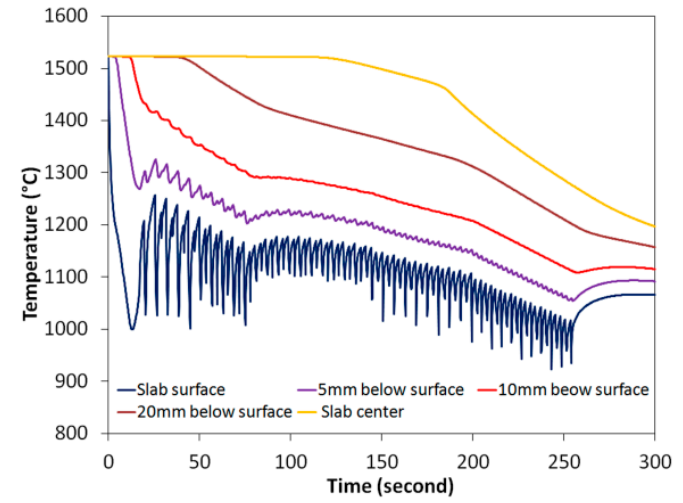

(c)

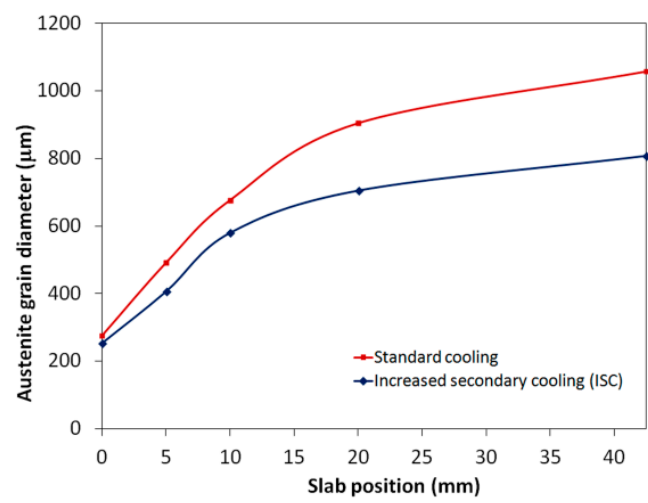

(d)

Figure 9. (a) the Algoma direct strip production complex (DSPC) model-predicted slab surface temperature using different secondary cooling set-ups; (b) the water loops configuration at Algoma DSPC; (c) the calculated $85 \mathrm{~mm}$ slab temperature profile using increased secondary cooling; and (d) comparison of $85 \mathrm{~mm}$ slab austenite grain sizes using standard cooling and increased secondary cooling.

\subsection{Liquid Core Reduction}

The TSCDR process at Algoma Inc. can adjust the strand gap dynamically during the casting process. The strand thickness can be reduced just below the mold by a tapered roll guide configuration of the " 0 " segment. Approximately a 10-30 mm strand reduction can be achieved with liquid core by means of many hydraulically-adjustable roll support segments. In this way, the slab thickness can be reduced from $98 \mathrm{~mm}$ to either 85 or $70 \mathrm{~mm}$ (Figure 10a). The liquid core reduction during casting produces a convective movement, which mixes the solidified dendrite structure and the liquid steel. A melt flow introduced by convection will generate strong shear stresses, which will shed away the newly formed dendrite arms near the solidification front. The newly formed dendrite crystals are then transported into the hot liquid pool by convective movement. Some of the dendrites are re-melted, while others survive and are transported back to the solidifying region. These surviving broken dendrite tips then form additional nucleation sites for delta-ferrite [32]. The finer delta-ferrite, in turn, will provide more nucleation sites for austenite during the delta-ferrite to austenite phase transformation resulting austenite grain refinement. This basic grain multiplication mechanism induced by liquid core reduction is shown schematically in Figure 10b.

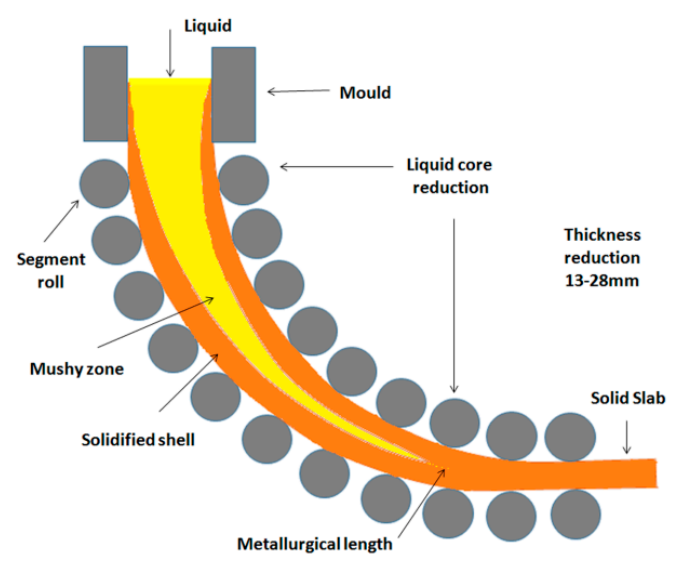

(a)

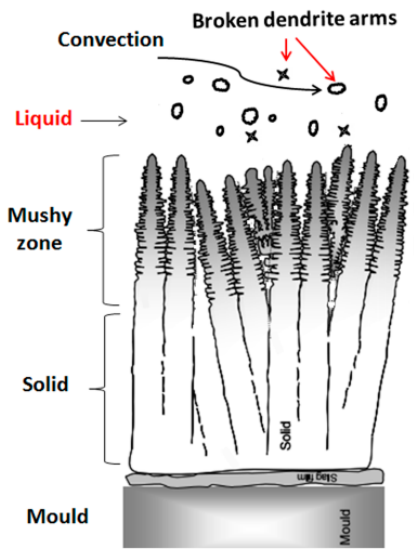

(b)

Figure 10. (a) Sketch diagram of liquid core reduction during thin-slab cast direct-rolling (TSCDR) process; (b) the basic mechanism of grain multiplication or grain refinement from liquid core reduction in the solidification region. The convective movement generates shear, to break the dendrite tips, and circulates the debris in the liquid pool. 
The liquid core reduction can not only refine as cast microstructure, but also can reduce center line segregation, as well as other solidification-related defects, such as shrinkages and porosity. The metallurgical length for HSLA steels is about $10.0 \mathrm{~m}$ which is at the end of segment "6". The liquid core reduction system together with a dynamic control of the liquid pool length can predict the best squeezing point during casting for these HSLA grades. For API X70, the liquid core reduction was set to occur at the fraction solid between $0.4-0.6$. Figure $11 \mathrm{a}, \mathrm{b}$ show API chemistry slab macro etch from strand 3 and strand 4 at the slab center position, respectively. The strand 3 slab sample shows centerline segregation and solidification shrinkages, which indicates that the squeezing was done late with higher solid fraction; however, the strand 4 sample had the diffused centerline, which confirms that the liquid core reduction was carried out at the optimum set point in the solid fraction.

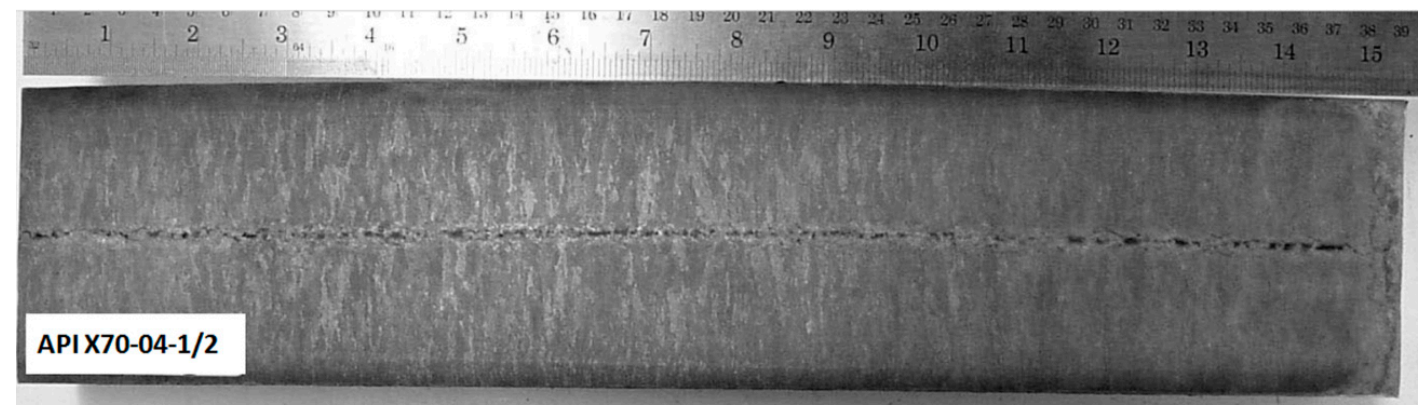

(a)

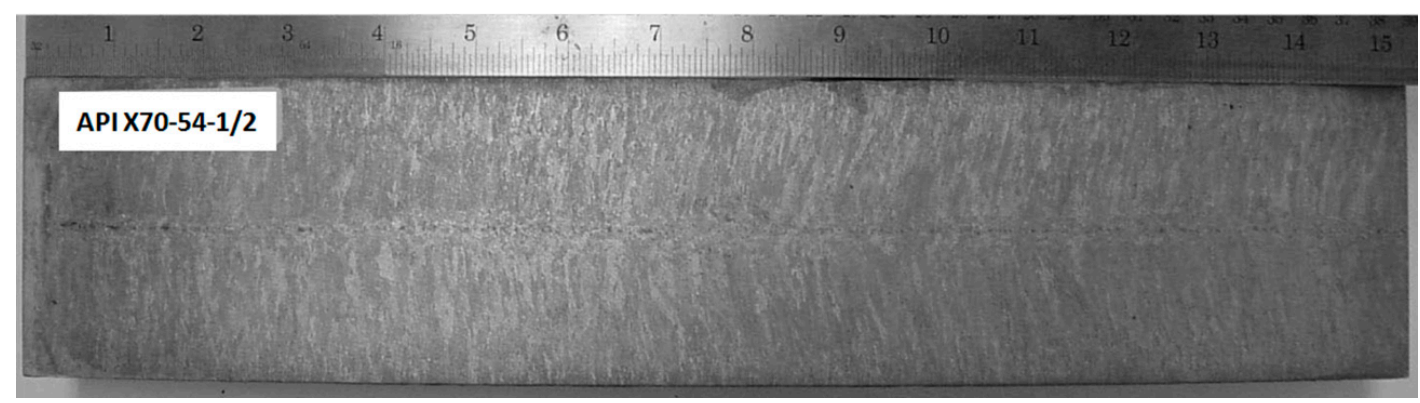

(b)

Figure 11. API X70 slab macro etch from: (a) strand 3; and (b) strand 4, with different set points of liquid core reductions.

3.4. Increasing the Number of Austenite Nucleation Sites during Delta-Ferrite to Austenite Phase Transformation

The HSLA steels are low carbon steels $(<0.08 \mathrm{wt} \%)$ which solidify as delta-ferrite. The ThermoCalc predicted the delta to austenite phase transformation was about $1477^{\circ} \mathrm{C}$ (Table 2 ) and occurred during the liquid core reduction stage. Very little information is available concerning the kinetics of this transformation and its effect on the grain size. To demonstrate the refinement of as-cast microstructure using deformation, the Fe-Al model alloy (Table 1) was studied using a quenching dilatometer at the CANMET Materials Technology Lab [33]. The specimen was reheated into the delta region for $60 \mathrm{~s}$; a compressive strain of 0.2 was applied, and then cooled to $1125^{\circ} \mathrm{C}$ at a cooling rate of $50{ }^{\circ} \mathrm{C} / \mathrm{s}$. The deformed sample was quenched to room temperature as soon as it reached $1125^{\circ} \mathrm{C}$. Figure 12a shows fine sub-grains that were present within the original delta-ferrite grains. Higher magnification SEM image (Figure 12b) confirmed that the sub-grain boundaries and the delta-ferrite grain boundaries were decorated by fine austenite precipitates. An electron backscatter diffraction (EBSD) map (Figure 12c) showed that austenite grains nucleated along the delta grain and sub-grain boundaries (red line is large angle grain boundary $\left(\theta>12^{\circ}\right.$ ) and the white is low angle grain boundary 
$\left.\left(12^{\circ}>\theta>2^{\circ}\right)\right)$. This demonstration suggested that sub-grains formed as a result of deformation prior to the delta-ferrite to austenite transformation. During this phase transformation, the sub-grain boundaries and the original delta grain boundaries provided nucleation sites for austenite grains, which would lead to the refinement of the austenite grain structure.

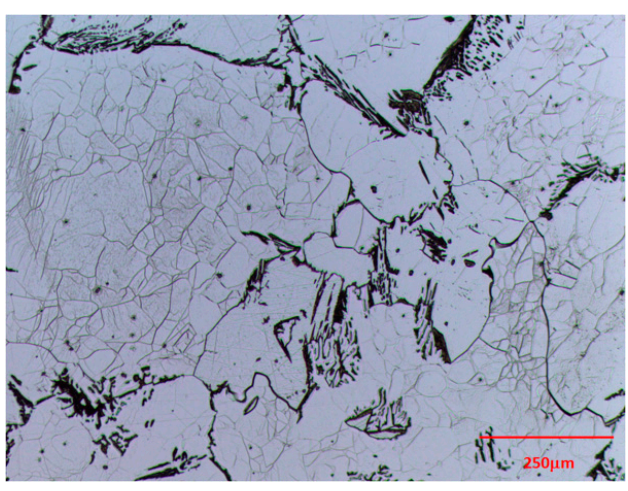

(a)

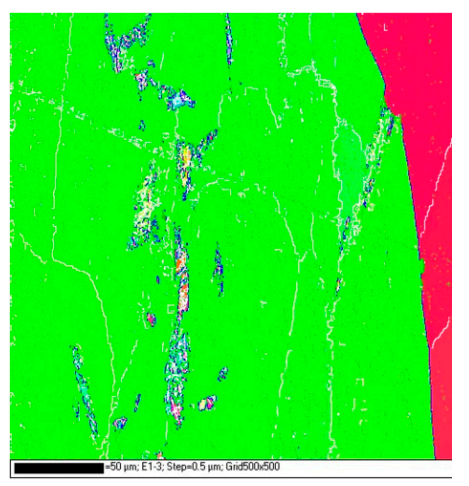

(c)

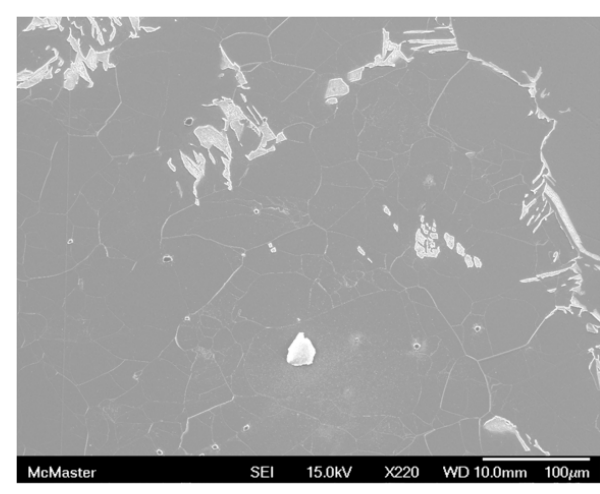

(b)

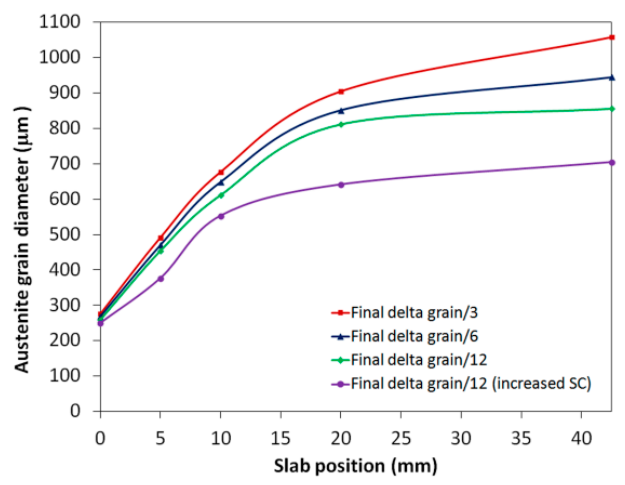

(d)

Figure 12. Microstructure of model Fe-Al alloy reheated into the delta region for $60 \mathrm{~s}$, a compressive strain of 0.2 was applied followed by cooling at $50{ }^{\circ} \mathrm{C} / \mathrm{s}$ to $1125^{\circ} \mathrm{C}$; the sample was quenched to room temperature as soon as it reached $1125^{\circ} \mathrm{C}$ : (a) Fine sub-grains present within the original delta-ferrite grains; (b) austenite nucleates along the original delta grain boundaries; (c) electron backscatter diffraction (EBSD) shows austenite grains nucleated along the delta grain and sub-grain boundaries, and $(\mathbf{d})$ predicted austenite grain size when the slab is about to enter the homogenization furnace, with different austenite nucleation sites.

To capture the effect of austenite nucleation sites on the austenite grain coarsening kinetics, the validated grain growth model can be used to calculate austenite grain evolution at different stages of the TSCDR process. Figure $12 \mathrm{~d}$ summarizes the predicted austenite grain sizes when the slab is about to enter the holding furnace for the different densities of austenite nucleation sites. The various lines represent the grain size achieved when 12,6 , and 3 austenite grains nucleate within each delta grain. The calculation reveals that these extra nucleation sites had little effect on the final grain size at the surface of the slab; however, the austenite grain did decrease with increasing the austenite nucleation sites; the austenite grain in the $85 \mathrm{~mm}$ slab center could be reduced from $1058 \mu \mathrm{m}$ to $945 \mu \mathrm{m}$ and $856 \mu \mathrm{m}$, respectively. The purple line in Figure 12d indicates the austenite grain size trend by using the austenite nucleation density 12 and increased secondary cooling. The austenite grain size in the slab center could be refined from 1058 to $705 \mu \mathrm{m}$. The calculated results predicted the potential of increasing the number of austenite nucleation sites during the delta-ferrite to austenite phase transformation to refine the austenite grain size. Much more work is still needed; however, 
to design new alloys and the deformation schedule during casting that could take advantage of this novel approach.

\subsection{Control of Holding Furnace Temperature and Holding Time}

Once the continuous slab leaves the secondary cooling zone it is cut to length and then sent to the roller hearth holding furnace, waiting for thermomechanical processing. The holding furnace standard set-up for HSLA at Algoma DSPC has a holding temperature of $1150{ }^{\circ} \mathrm{C}$ for $18 \mathrm{~min}$. Austenite grains continue to coarsen inside the holding furnace. The experimental measurement of austenite grain size from the 85 and $70 \mathrm{~mm}$ slabs (Figures $2 \mathrm{~d}$ and $3 \mathrm{~d}$ ) were used as the initial grain size, and the effects of holding temperature and time on austenite grain coarsening by using Equations (2) and (4) are summarized in Figure 13.

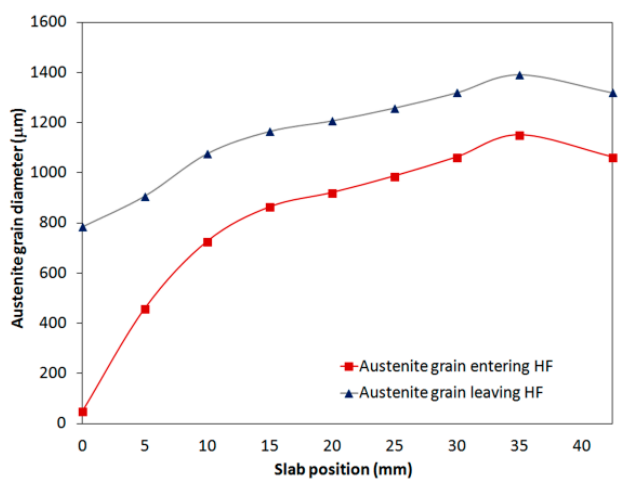

(a)

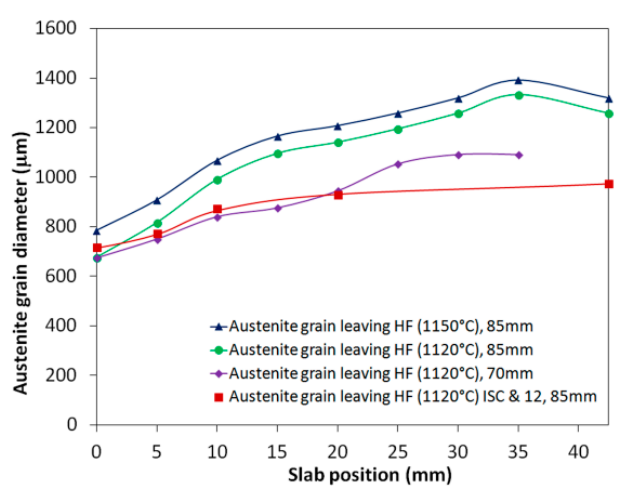

(c)

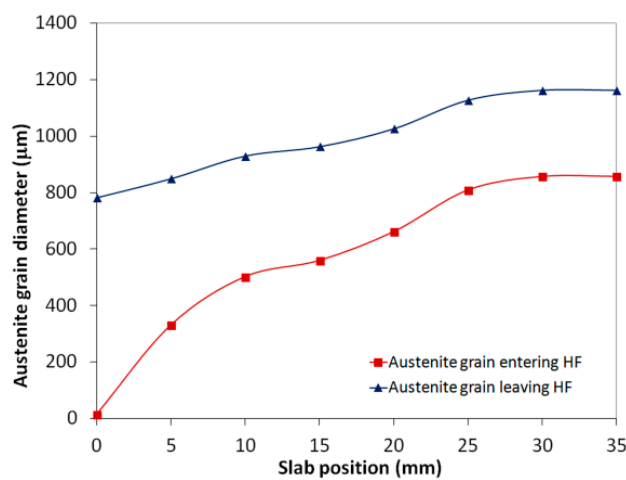

(b)

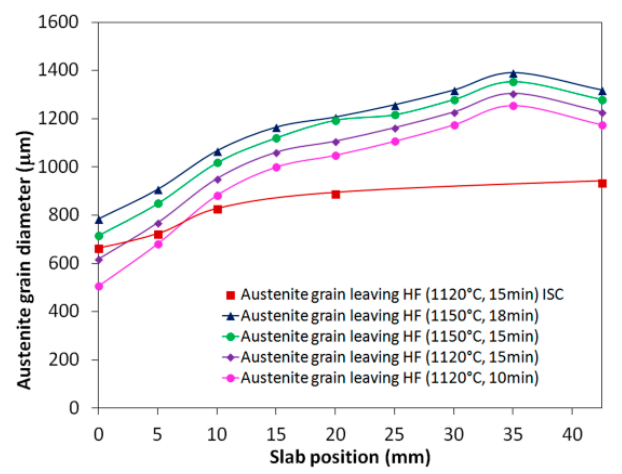

(d)

Figure 13. (a) Comparison of DSPC 85-mm thick slab austenite grain size before entering and after leaving the holding furnace $\left(1150^{\circ} \mathrm{C}, 18 \mathrm{~min}\right)$; (b) comparison of DSPC 70-mm thick slab austenite grain size before entering and after leaving the holding furnace $\left(1150{ }^{\circ} \mathrm{C}, 18 \mathrm{~min}\right)$; (c) the effect of holding temperature 1120 and $1150{ }^{\circ} \mathrm{C}$ on austenite size after leaving the holding furnace; and (d) the effect of holding time and temperature on austenite grain size after leaving the holding furnace.

Figure 13a shows that, for a DSPC $85 \mathrm{~mm}$ slab, austenite grain diameter increased from 50 to $784 \mu \mathrm{m}$ at the slab surface and from 1161 to $1391 \mu \mathrm{m}$ in the slab center when the slabs were held at $1150{ }^{\circ} \mathrm{C}$ for 18 minutes. Extremely large austenite grains existed at the slab center before thermomechanical processing. Austenite grains coarsen much faster on the slab surface than in the slab center due to the larger driving force on the surface. Austenite grain size close to the center of the slab could be reduced from 1391 to $1161 \mu \mathrm{m}$ by casting a $70 \mathrm{~mm}$ slab instead of $85 \mathrm{~mm}$ slab (Figure 13b). The effect of holding temperatures on austenite coarsening kinetics is shown in Figure 13c. Once again, the experimental measurement data were used as initial grain size, and the holding time, 
$18 \mathrm{~min}$, was used for the calculation. The austenite grain size could be reduced from 1391 to $975 \mu \mathrm{m}$ if increased secondary cooling was used, as well as using the austenite nucleation density 12 during the delta-ferrite to austenite phase transformation when casting an $85 \mathrm{~mm}$ slab. The effect of holding time at 1150 and $1120^{\circ} \mathrm{C}$ is summarized in Figure $13 \mathrm{~d}$. The best combination to control austenite coarsening was to use increased secondary cooling during casting and to set up the holding furnace at $1120{ }^{\circ} \mathrm{C}$ for $15 \mathrm{~min}$; thus, the austenite grain size could be reduced from 1391 to $935 \mu \mathrm{m}$.

\subsection{The Possibility of Producing a New Alloy with Two-Phase Pinning}

To refine HSLA steels' austenite grain size during the TSCDR process, carbides/nitrides of Ti, $\mathrm{Nb}$, and $\mathrm{V}$ are extensively used to retard grain growth at high temperatures [34,35]. However, these precipitates are ineffective at pinning grain growth when the steel is held at a high temperature for a long time, due to the dissolution of fine particles and rapid particle coarsening. Zhou et al [36,37] proposed a new steel system that can automatically pin the delta grain growth by using a small volume fraction of austenite phase at high temperature. The grain growth is controlled by the austenite phase coarsening rate, which is determined by the bulk diffusion.

Figure 14a shows the CON1D calculated temperature profile at the slab surface as well as those at 5 and $10 \mathrm{~mm}$ below the surface of an $85 \mathrm{~mm}$ API X70 slab, at Algoma Inc., using the DSPC process cast at a speed of $3.4 \mathrm{~m} / \mathrm{min}$. The recorded thermal profile obtained from the laboratory solidification experiment using the new Fe-Al model alloy (Table 1) was superimposed for comparison. The reordered cooling rates, using water quenching, forced air cooling, air cooling, and in mold cooling used in the lab processing were similar to the cooling rates calculated at the slab surface, 5 and $10 \mathrm{~mm}$ below the surface, and at the slab center of the TSDCR cast $85 \mathrm{~mm}$ slab. In this way, one can compare the average grain sizes obtained from the solidification simulation tests to the grain-sizes measured at 0,5 , and $10 \mathrm{~mm}$ below the surface and the center of the industrial slab. These comparisons are shown in Figure 14b, in which the grain-size prior to entry into the soaking furnace was obtained by directly measuring the prior austenite grain size as a function of distance from the surface of the slab (Figure 2d). The data points for the new steel were positioned by matching the cooling rates in the solidification simulation test to the position at which these cooling rates would be observed within the slab. It can be seen that the expected grain size at the center would be $280 \mu \mathrm{m}$, compared to $1475 \mu \mathrm{m}$ for API X70, if the new steel was cast in the form of an $85 \mathrm{~mm}$ slab. This clearly demonstrates the potential advantage of this new alloy. One could also compare the grain-sizes within the API X70 slab after exiting the soaking furnace, to those expected in the new alloy, and observe that the grain size of the new alloy was essentially unchanged as a result of soaking, which can prevent excessive grain growth prior to the onset of thermomechanical processing.

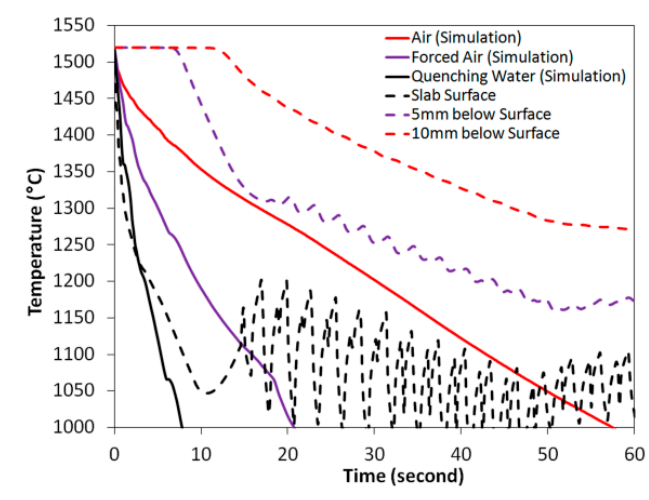

(a)

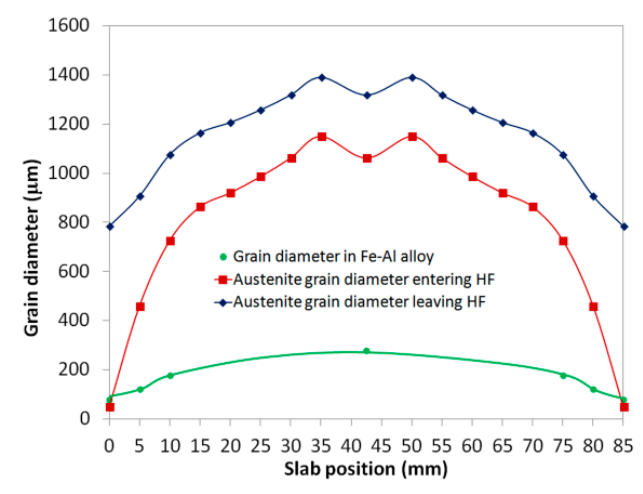

(b)

Figure 14. (a) Comparison of CON1D predicted temperature profiles on the surface and 5 and $10 \mathrm{~mm}$ below the API X70 $85 \mathrm{~mm}$ slab, and the recorded thermal profile during simulation process [37]; (b) comparison of grain size evolution with slab distance using the TSCDR process to produce API X70 and Fe-Al new alloy. 


\section{Conclusions}

The developed grain growth model successfully reproduced grain growth as a function of position within the API X70 slab in the TSCDR process. The results suggest that it is essential to control grain coarsening in each step, from solidification to the holding furnace, in order to maintain a required fine and uniform austenite grain size prior to the onset of thermomechanical processing.

Reducing the slab thickness can increase the cooling rate at the slab center during the TSCDR process. Predictions of the grain growth model suggest that austenite grain diameter can be reduced from 1345 to $500 \mu \mathrm{m}$ if a $30 \mathrm{~mm}$ slab high cooling rate is produced. In addition, this would lead to less non-uniformity in the as-cast microstructure by refining the grains at the center of the slab. Increasing secondary cooling with restricted casting speed will increase cooling rate, resulting in primary and secondary dendrite arm spacing refinement. Increased secondary cooling, from $0.6 \mathrm{~L} / \mathrm{kg}$ of hot steel to $1.4 \mathrm{~L} / \mathrm{kg}$ of hot steel, can reduce the grain size at the center of an $85-\mathrm{mm}$ thick slab, from 1345 to $942 \mu \mathrm{m}$.

Liquid core reduction together with dynamic control of the liquid pool length can not only reduce center line segregation and solidification-related defects, but also provides the potential for generating more nucleation sites for delta-ferrite resulting in austenite grain refinement.

Increasing the number of austenite nucleation sites during the delta-ferrite to austenite phase transformation is an effective method of refining and homogenizing the as-cast microstructure of the TSCDR micro alloyed steels. When the Fe-Al model alloy was deformed prior to the onset of the delta to gamma transformation austenite, nucleated prolifically along the original delta grain boundaries and the newly recrystallized delta grain boundaries. The application of $20 \%$ deformation generated more than 30 recrystallized grains in each original delta grain. The calculations confirmed that the austenite grain in the $85 \mathrm{~mm}$ slab center can be reduced from 1345 to $1001 \mu \mathrm{m}$ by doubling the nucleation sites.

Austenite grains continue growing inside the holding furnace. Optimizing the holding temperature and time can control austenite coarsening. The austenite grain size can be reduced from 1475 to $1072 \mu \mathrm{m}$ if casting a $70 \mathrm{~mm}$ slab with a soaking temperature of $1120^{\circ} \mathrm{C}$ for $10 \mathrm{~min}$, instead of $1150{ }^{\circ} \mathrm{C}$ for $18 \mathrm{~min}$.

The use of a delta-ferrite/austenite duplex microstructure is an effective method to retard grain growth at high temperatures. In the delta-ferrite/austenite duplex microstructure, the delta grain growth rate is very slow and controlled by the rate of coarsening of second phase particles. The developed grain growth model predicts that the delta grain size is 10 times smaller in a duplex microstructure than that in materials without pinning. Laboratory validation shows that the delta grains are pinned throughout the TSCDR process, starting from the final stages of solidification. The concept of dual phase to retard grain coarsening, as demonstrated by the delta-ferrite/austenite duplex microstructure, has great potential for producing more uniform as-cast microstructure for the TSCDR process.

Author Contributions: Conceptualization, T.Z., H.S.Z., and M.S.; methodology, T.Z., H.S.Z., M.S., and R.J.O.; software, R.J.O.; validation, T.Z., H.S.Z., and R.J.O.; formal analysis, T.Z., H.S.Z., and R.J.O.; investigation, T.Z., H.S.Z., and R.J.O.; resources, S.-H.C. and P.Z.; data curation, T.Z. and R.J.O.; writing-original draft preparation, T.Z.; writing-review and editing, R.J.O. and M.S.; visualization, H.S.Z.; supervision, H.S.Z. and M.S.; project administration, M.S.; funding acquisition, M.S.

Funding: This research received no external funding.

Acknowledgments: The authors wish to acknowledge with thanks (i) technical support in making model alloys by CANMET (Hamilton, ON, Canada), (ii) assistance in material characterization from Canadian Centre for Electron Microscopy (CCEM) at McMaster University (Hamilton, ON, Canada), and (iii) the technological support from the DSPC operation team and New Product Development Department at Algoma Inc. (Sault Ste. Marie, ON, Canada).

Conflicts of Interest: The authors declare no conflict of interest. 


\section{Appendix A}

To calculate the grain boundary mobility $M(t)$ in Equation (A1), the Turnbull mobility was used as an initial estimation:

$$
M_{\text {pure }}=\frac{w D_{\mathrm{GB}} V_{\mathrm{m}}}{\boldsymbol{b}^{2} R T}
$$

In the above equation, $w$ is the grain boundary thickness, $D_{\mathrm{GB}}$ is the grain boundary self-diffusion coefficient, $V_{\mathrm{m}}$ is the molar volume, $\boldsymbol{b}$ is the magnitude of the Burgers vector, $R$ is the gas constant and $T$ is the absolute temperature. The delta-ferrite has body-centered-cubic (BCC) crystal structure, the Burgers vector is $\boldsymbol{b}=1 / 2<111>$ and $b=\sqrt{3} a / 2$, where $\boldsymbol{a}$ is the lattice parameter of delta-ferrite, $0.286 \mathrm{~nm}$. The molar volume, $V_{m}=7.11 \mathrm{~cm}^{3}$. The activation energy for diffusion along the grain boundary was taken to be $Q_{\mathrm{GB}}=0.68 \mathrm{Q}$, where $Q=256 \mathrm{~kJ} / \mathrm{mole}$ is the activation energy for bulk diffusion in BCC. Finally, $w=1 \mathrm{~nm}$ and $Q_{\mathrm{GB} 0}=1.67 \times 10^{-4} \mathrm{~m}^{3} / \mathrm{s}$. Given that Turnbull mobility does not take into account attachment kinetics, the grain boundary mobility in this way overestimates the experimental grain growth kinetics. The best fit of the experimental data was obtained using a mobility, which is $1 / 3$ of the Turnbull estimate [9]. Therefore, the delta grain mobility used in this work was:

$$
M_{\delta}(t)=\frac{0.7075}{T(t)} \times \exp \left(\frac{-20,995.43}{T(t)}\right)
$$

To estimate the mobility of the austenite grain boundaries, the austenite with face-centered cubic (FCC) crystal structure has $b=1 / 2<110>$; therefore, $b=\sqrt{2} a / 2$, where $a$ is $0.357 \mathrm{~nm}$. The molar volume, $V_{\mathrm{m}}$, is $6.85 \mathrm{~cm}^{3}$, the bulk diffusion activation energy in FCC $Q=284 \mathrm{~kJ} / \mathrm{mole}$, and that of grain boundary diffusion is: $Q_{\mathrm{GB}}=0.61 Q . w=1 \mathrm{~nm}$ and $Q_{\mathrm{GB} 0}=0.49 \times 10^{-4} \mathrm{~m}^{3} / \mathrm{s}$. Once again, the Turnbull mobility leads to an overestimation of the austenite grain growth kinetics. The best fit of the experimental data was obtained with a mobility, which is 0.96 times the Turnbull estimate [9]. Thus, the austenite grain boundary mobility used in this calculation was:

$$
M_{\gamma}(t)=\frac{0.3072}{T(t)} \times \exp \left(\frac{-20,837.14}{T(t)}\right)
$$

The cooling path $T(t)$ at each point of the slab and secondary dendrite arm spacing, thermophysical properties, and spray heat transfer coefficients were calculated using the CON1D V7.0 slab casting heat transfer model. The casting speeds for different slab thicknesses used in the simulations are listed as the following:

(1) $85 \mathrm{~mm}$ slab, casting speed 3.0-3.4 m/min;

(2) $70 \mathrm{~mm}$ slab, casting speed $3.4-4.0 \mathrm{~m} / \mathrm{min}$;

(3) $50 \mathrm{~mm}$ slab, casting speed $4.5-5.5 \mathrm{~m} / \mathrm{min}$;

(4) $30 \mathrm{~mm}$ slab, casting speed $4.5-6.5 \mathrm{~m} / \mathrm{min}$.

\section{References}

1. Klinkenberg, C.; Kintscher, B.; Hoen, K.; Reifferscheid, M. More than 25 years of experience in thin slab casting and rolling current state of the art and future developments. Steel Res. Int. 2017, 88, 1700272. [CrossRef]

2. Arvedi, G.; Mazzolari, F.; Siegl, J.; Hohenbichler, G.; Holleis, G. Arvedi ESP first thin slab endless casting and rolling results. Ironmak. Steelmak. 2010, 37, 271-275. [CrossRef]

3. Zhou, T.; Zhang, P.; Kuuskman, K.; Cerilli, E.; Cho, S.H.; Burella, D.; Zurob, H.S. Development of medium-high carbon hot rolled steel strip on a thin slab casting direct strip production complex. Ironmak. Steelmak. 2018, 45, 603-610. [CrossRef]

4. Bhattacharya, D.; Misra, S. Development of microalloyed steels through thin slab casting and rolling (TSCR) route. Trans. Indian Inst. Met. 2017, 70, 1647-1659. [CrossRef] 
5. Challa, V.S.A.; Misra, R.D.K.; O'Malley, R.; Jansto, S.G. The Effect of Coiling Temperature on the Mechanical Properties of Ultrahigh-Strength $700 \mathrm{MPa}$ Grade Processed via Thin-Slab Casting. In Proceedings of the AISTech 2014 Proceedings, Indianapolis, IN, USA, 5-8 May 2014; pp. 2987-2997.

6. Nie, W.J.; Xin, W.F.; Xu, T.M.; Shi, P.J.; Zhang, X.B. Enhancing the toughness of heavy thick X80 pipeline steel plates by microstructure control. Adv. Mater. Res. 2011, 194-196, 1183-1191. [CrossRef]

7. Reip, C.P.; Hennig, W.; Kempken, J.; Hagmann, R. Development of CSP processed high strength pipe steels. Mater. Sci. Forum. 2005, 500-501, 287-294. [CrossRef]

8. Wang, R.; Garcia, C.I.; Hua, M.; Zhang, H.; DeArdo, A.J. The Microstructure Evolution of Nb,Ti Complex Microalloyed Steel During the CSP Process. Mater. Sci. Forum. 2005, 500-501, 229-236. [CrossRef]

9. Zhou, T.; O'Malley, R.J.; Zurob, H.S. Study of grain-growth kinetics in delta-ferrite and austenite with application to thin-slab cast direct-rolling microalloyed steels. Metall. Mater. Trans. A 2010, 41, 2112-2120. [CrossRef]

10. Martin, J.W.; Doherty, R.D.; Cantor, B. Stability of Microstructure in Metallic Systems; Cambridge University Press: Cambridge, UK, 1997; pp. 219-231.

11. Humphreys, F.J.; Hatherly, M. Recrystallization and Related Annealing Phenomena, 2nd ed.; Elsevier Ltd.: Oxford, UK, 2004; pp. 11-25.

12. Turnbull, D. Theory of grain boundary motion. Trans. AIME 1951, 191, 661-665.

13. Köthe, A.; Kunze, J.; Backmann, G.; Mickel, C. Precipitation of TiN and (Ti,Nb)(C,N) during solidification, cooling and hot direct deformation. Mater. Sci. Forum. 1998, 284-286, 493-500. [CrossRef]

14. Nagata, M.T.; Speer, J.G.; Matlock, D.K. Titanium nitride precipitation behavior in thin-slab cast high-strength low-alloy steels. Metall. Mater. Trans. A 2002, 33, 3099-3109. [CrossRef]

15. Smith, C.S. Grains, Phases, and interfaces: An interpretation of microstructure. Trans. Metall. Soc. AIME 1948, 175, 15-51.

16. Kwon, O.; DeArdo, A.J. Interactions between recrystallization and precipitation in hot-deformed microalloyed steels. Acta Metall. 1991, 39, 529-538. [CrossRef]

17. Palmiere, E.J.; Garcia, C.I.; DeArdo, A.J. Compositional and microstructural changes which attend reheating and grain coarsening in steels containing niobium. Metall. Mater. Trans. A 1994, 25, 277-286. [CrossRef]

18. Poths, R.M.; Rainforth, W.M.; Palmiere, E.J. Strain Induced precipitation in model and conventional microalloyed steels during thermomechanical processing. Mater. Sci. Forum. 2005, 500-501, 139-145. [CrossRef]

19. Zurob, H.S.; Hutchinson, C.R.; Brechet, Y.; Purdy, G. Modeling recrystallization of microalloyed austenite: Effect of coupling recovery, precipitation and recrystallization. Acta Mater. 2002, 50, 3075-3092. [CrossRef]

20. Gladman, T. The Physical Metallurgy of Microalloyed Steel; Institute of Metals: London, UK, 1997.

21. Thermo-Calc Software. Available online: www.thermocalc.com (accessed on 2 November 2018).

22. Meng, Y.; Thomas, B.G. Heat-transfer and solidification model of continuous slab casting: CON1D. Metall. Mater. Trans. B 2003, 34, 685-705. [CrossRef]

23. Yin, H.; Emi, T.; Shibara, H. Morphological Instability of $\delta$-ferrite $/ \gamma$-austenite interphase boundary in low carbon steel. Acta Mater. 1999, 47, 1523-1535. [CrossRef]

24. Kim, H.S.; Kobayashi, Y.; Nagai, K. Prediction of prior austenite grain size of high-phosphorous steels through phase transformation simulation. ISIJ Int. 2006, 46, 854-858. [CrossRef]

25. Holzhauser, J.F.; Spitzer, K.H.; Schwerdtfeger, K. Study of heat transfer through layers of casting flux: experiments with a laboratory set-up simulating the conditions in continuous casting. Steel Res. 1999, 70, 252-257. [CrossRef]

26. Gonzalez, M.; Goldschmit, M.B.; Assanelli, A.P.; Berdaguer, E.F.; Dvorkin, E. Modeling of the solidification process in a continuous casting installation for steel slabs. Metall. Mater. Trans. B 2003, 34, 455-473. [CrossRef]

27. Louhenkilpi, S.; Makinen, M.; Vapalahti, S.; Raisanen, T.; Laine, J. 3D steady state and transient simulation tools for heat transfer and solidification in continuous casting. Mater. Sci. Eng. A 2005, 413-414, 135-138. [CrossRef]

28. McCarrney, D.G.; Hunt, J.D. Measurements of cell and primary dendrite arm spacing in directionally solidified aluminum alloys. Acta Metall. 1981, 29, 1851-1863. [CrossRef]

29. Bouchard, D.; Kirkaldy, J.S. Prediction of dendrite arm spacings in unsteady and steady-state heat flow of unidirectionally solidified binary alloys. Metall. Mater. Trans. B. 1997, 28, 651-663. [CrossRef] 
30. Taha, M.A. Influence of solidification parameters on dendrite arm spacings in low carbon steels. J. Mater. Sci. Lett. 1986, 5, 307-310. [CrossRef]

31. Cahn, R.W.; Haasen, P. Physical Metallurgy, 4th ed.; North-Holland Physics Publishing: Amsterdam, The Netherlands, 1996.

32. Sobral, M.D.C.; Mei, P.R.; Santos, R.G.; Gentile, F.C.; Bellon, J.C. Laboratory simulation of thin slab casting. Ironmak. Steelmak. 2003, 30, 412-416. [CrossRef]

33. Zhou, T.H.; Gheribi, A.E.; Zurob, H.S. Austenite particle coarsening and delta-ferrite grain growth in model Fe-Al alloy. Can. Metall. Q. 2013, 52, 90-97. [CrossRef]

34. Zhou, T.; Overby, D.; Badgley, P.; Martin-Root, C.; Wang, X.; Liang, S.L.; Zurob, S.H. Study of processing, microstructure and mechanical properties of hot rolled ultra high strength steel. Ironmak. Steelmak. 2018. [CrossRef]

35. Hillert, M. Inhibition of grain growth by second-phase particles. Acta Metall. 1988, 36, 3177-3181. [CrossRef]

36. Zhou, T.; Zurob, H.S.; O'Malley, R.J.; Rehman, K. Model Fe-Al steel with exceptional resistance to high temperature coarsening. Part I: Coarsening mechanism and particle pinning effects. Metall. Mater. Trans. A 2015, 41, 178-189. [CrossRef]

37. Zhou, T.; Zhang, P.; O'Malley, R.J.; Zurob, H.S.; Subramanian, M. Model Fe-Al steel with exceptional resistance to high temperature coarsening. Part II: Experimental validation and applications. Metall. Mater. Trans. A 2015, 41, 190-198. [CrossRef]

(C) 2019 by the authors. Licensee MDPI, Basel, Switzerland. This article is an open access article distributed under the terms and conditions of the Creative Commons Attribution (CC BY) license (http://creativecommons.org/licenses/by/4.0/). 